\title{
A Study on Organizational Commitment of Police Employees
}

\author{
Abhay Pratap Singh ${ }^{1}$
}

\section{ABSTRACT}

In the present study, an effort has been made to investigate the level of organizational commitment in police personnel. A 3x2 factorial design with three levels of job hierarchy (i.e., officers, sub inspectors \& constables) and two levels of job tenure (i.e., short job tenure \& long job tenure) was used. A total of 240 police employees were randomly selected from various police stations of Eastern U.P. Organizational commitment scale (Allen \& Meyer, 1990) was used to determine the level of organizational commitment in employees.

Results revealed that the extent of organizational commitment varied significantly in various group of police employees. Affective commitment was found greater in officers than sub inspectors and constables respectively. Whereas, normative commitment was found greater in officers and sub-inspectors as compared to constables. Long job tenure group reported high level of normative commitment as compared to short job tenure group .Overall organizational commitment was found maximum in officers as compared to sub-inspectors and constables. Long job tenure group reported high level of overall commitment as compared to short job tenure group. Interaction effects of job hierarchy and job tenure on normative and overall organizational commitment were also found. Results have been discussed in the light of individual and organizational factors.

Keywords: Affective, Continuance, Hierarchy, Normative, Tenure, Organizational Commitment

Many organizations say that their employees are the greatest agent and asset of their success. When we discuss about police organization's functioning, we find that it is very hard working organization, we encounter notions such as organizational effectiveness, organizational efficiency, job performance, payment, working hours etc. However the notion of organizational commitment is overlooked, although it is the much importance to organizational functioning. It is fact that police employees usually work in unpredictable situations like group violence, communal violence, murder etc, where they experience stress and frustrations, poor interpersonal relation between officers and followers, excess working hours and poor working places may go down the level of commitment, adjustment and so on.

Researchers defined organizational commitment as the degree of an individual's relations and experiences as a sense of loyalty toward one's organization. In addition to loyalty, organizational

\footnotetext{
${ }^{1}$ Assistant Professor, Dept. of Psychology Akhilabhagya Post Graduate College Ranapar, Gorakhpur (C) 2015 I A Singh; licensee IJIP. This is an Open Access Research distributed under the terms of the Creative Commons Attribution License (http://creativecommons.org/licenses/by/2.0), which permits unrestricted use, distribution, and reproduction in any Medium, provided the original work is properly cited.
} 


\section{A Study on Organizational Commitment of Police Employees}

commitment encompasses an individual's willingness to extend effort in order to further an organizations goal and the degree of alignment the organization has with the goals and values of the individual (Mowday, et.al.1979). Allen and Meyer (1996) have defined organizational commitment as a psychological link between an employee and his organization that makes it less likely that the employee will voluntarily leave the organization. Organizational commitment refers to the extent to which an employee develops an attachment and feels a sense of allegiance to his or her employer (The Pennsylvania State University, 2011).

Meyer and Allen (1991) proposed a three component model of organizational commitment viz; affective commitment, continuance commitment and normative commitment. 1. Affective commitment refers to the employee's emotional attachment to identification with and involvement in the organization ('Want to'). Employees with strong affective commitment continue employment with the organization because they are bound by their emotions to do so 2.Continuance commitment refer to an awareness of the costs associated with leaving the organization (need to ). 3. Normative commitment reflects a feeling of obligation to continue employment ('ought to') or Organizational Retaliatory Behavior (ORB). Employees with high level of normative commitment feel that they ought to remain with the organization by virtue of their belief that it is the right and moral thing to do (Meyer \& Allen, 1991 ; Scholl, 1981 ; Weiner, 1982).

Literature suggests that employee's personality and organizational factors may be an important antecedent to organizational commitment. Randall (1990) found that white collar workers have more commitment at work than blue collar workers. The studies of employed persons in actual work setting (Bruning and Snyder,1981; Snyder and Bruning, 1979) also showed that 'position' characteristics are primary determinants of an individual's work related sense of commitment. Study conducted on a public sector unit revealed that executives were more committed to their organization than supervisors (Pattanayak, Mishra and Mishra, 1993). Mc Caul et al (1995) found a relationship between organizational commitment and hierarchical level. Benkhoff (1997) also found organizational commitment to increase with hierarchical position in an organization. Some evidence proved that years in position and years of experience are positively associated with commitment. Previous studies have indicated that position tenure (Gregersen and Black,1992; Mottaz,1988) and organizational tenure (Mathieu and Hammel,1989; Mathieu and Zajac ,1990 ) have small but positive effects on commitment. The length of service in an organization is positively related to the level of internalization of organizational values, which results in greater commitment from the individual( Allen and Meyer,1990;Hettriegel et al, 1995; O’Reilly et al., 1991 )

Mathieu and Zajac (1990) have grouped antecedents of commitment into two categories: 1.Personal Characteristics i.e., Age, Sex, Education, Marital Status, Tenure, Perceived Competence, Ability, Salary, Other Factors 2: Situational factor i.e., Group Dynamics, Job Characteristics, Organizational characteristics, Role States, Social involvement and perceived pay equity. 


\section{A Study on Organizational Commitment of Police Employees}

Researchers have confirmed that individually valued variables such as need satisfaction , managerial respect, intrinsic motivation, work outcome measures, job satisfaction (Bhattacharya and Verma , 1988; Mohan and Srivastava,1986 ; Steers, 1977; Verma , 1986 ; Weiner and Vardi, 1980) and organizationally valued variables such as performance level of employees, turnover, organizational culture/climate, organizational adaptability discipline value and performance value (Amsa and Punekar , 1985; Angd and Perry, 1981;Padaki and Gandhi,1981; Singh and Das , 1978; Steers, 1977) are both mutually related to organizational commitment.

Despite the vast amounts of researches on employee's organizational commitment are still do not know very much about the factors that explain the phenomenon. In context, very few studies particularly on Indian police sample have tested in the context of hierarchical level and job tenure. Indeed, employee attachment and commitment can be varied not only with organization, but also other factors, such as type of job position, job tenure and so on within the job.

After review of earlier studies and some general observation of police functioning of Gorakhpur zone, this study was planned to investigate 'the role of job hierarchy and job tenure on organizational commitment of police personnel '

\section{OBJECTIVE:}

1. To examine the role of job hierarchy and job tenure on organizational commitment of police employees.

\section{HYPOTHESIS:}

1) The job hierarchy (officers, sub-inspectors \& constables) and job tenure (short job tenure and long job tenure) would exercise impact on organizational commitment..

\section{METHOD}

\section{Design:}

This study is based on a 3x2 factorial design with three level of job hierarchy i.e., Officers, SubInspectors, and Constables and job tenure i.e., Short Job Tenure (below 5 years) and Long Job tenure (above 10 years).

\section{Sample:}

A total of 240 male police personnel participated as respondents in this study. Stratified random sampling technique was used. The sample was selected from various Thana, traffic offices, fire stations, PAC offices of Gorakhpur Zone. 


\section{A Study on Organizational Commitment of Police Employees}

\section{Measuring Tools:}

Personal Data Sheet: P.D.S was used to collect the background information.

Organizational Commitment Scale (OCS) : The revised scale of organizational commitment (Allen \& Meyer, 1990a) was used to ascertain organizational commitment. The original scale comprises of 8 items each (Allen \& Meyer, 1990a) on the three dimensions. The revised scale comprises of 6 items on each of the three dimensions and hence, consists of 18 items. To adapt in Indian culture the English version of the Meyer, Allen and Smith (1993) scale was translated in Hindi and finally, Indian adaptation of organizational commitment scale, made by Khan and Mishra, (2002) was used in this study. This scale contains three components of commitment i.e. affective, continuance and normative.

\section{Scoring:}

Originally, the scale was 5 point Likert Scale. There were four negatively worded items, three in affective commitment and one in normative commitment sub-scales. The negatively worded items are to be scored in reverse order i.e., 5, 4, 3, 2, 1 order. The responses of the identified items were added to generate dimension wise and overall organizational commitment. Thus, the possible score for commitment sub scale would be 6 to 30 and for overall organizational commitment scale from 18 to 90. High score indicates high level of agreement and low score indicates low agreement on commitment dimensions in the organization.

\section{Procedure:}

Participants were contacted at their workplaces. They were introduced about the problem of the study. Each participant was promised that his personal views and information would not be disclosed at any cost. After receiving the initial willingness of the respondents to participate in the study, their background information's were collected on the basis of Personal Data Sheet (P.D.S). Then, they were requested to respond on organizational commitment scale. As soon as, they completed their responses on above said measures, data were collected and respondents were thanked for participation. Obtained data were scored according to defined rules as given in manuals.

\section{RESULTS}

The scores were found on the basis of responses given by police personnel on Organizational Commitment Scale. Obtained scores were treated statistically in terms of Mean, S.D and ANOVA Analysis. Results are displayed in Table 1 and Figures 1,2,3,4,5,6,7 \& 8 
Table 1: Shows Means, SDs and F- Values of organizational commitment as a function of job hierarchy and job tenure

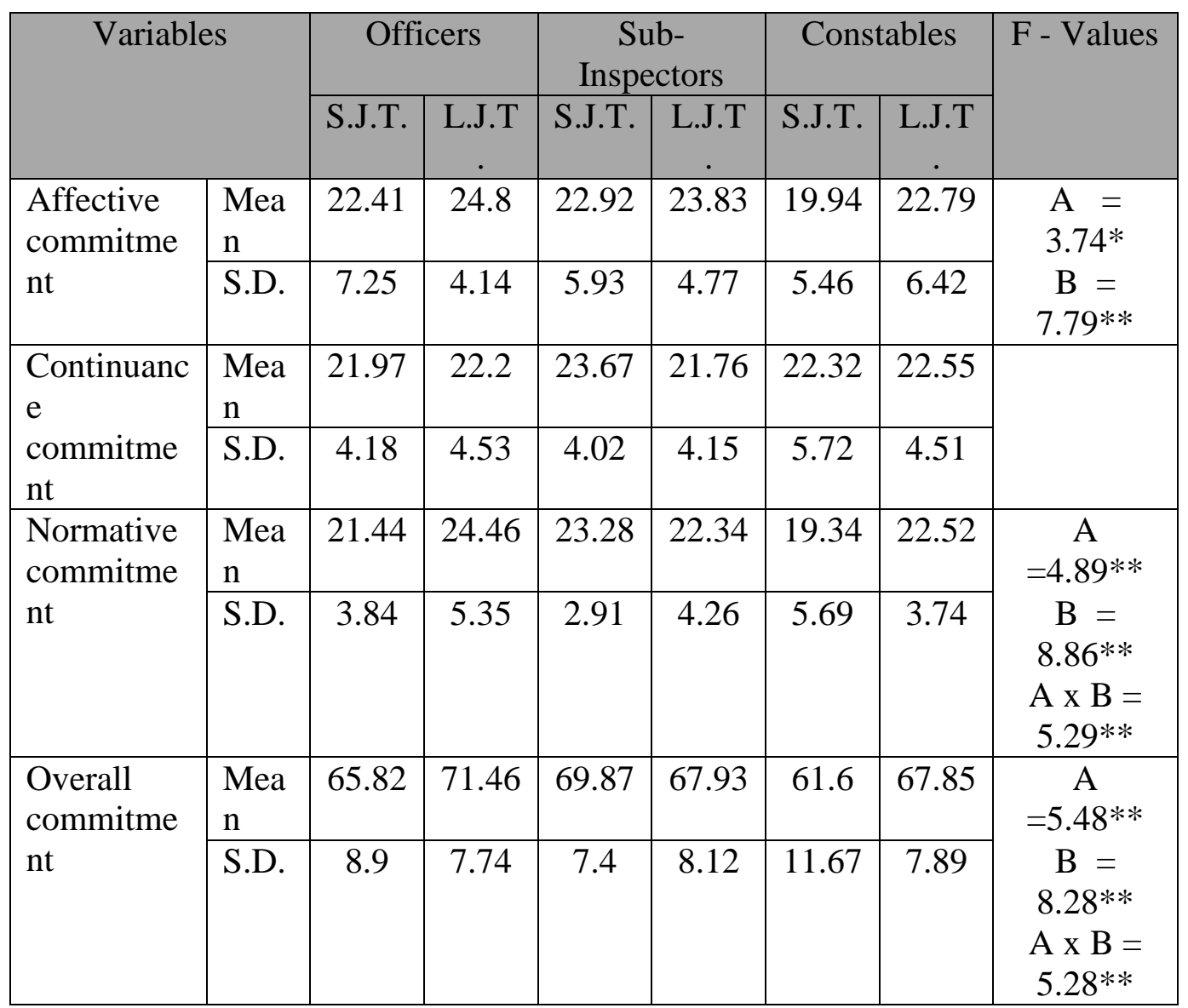

$\mathrm{N}=$ 240, S.J.T. $=$ Short Job Tenure, L.J.T. $=$ Long Job Tenure, $\mathrm{N}=240,{ }^{* *}=\mathrm{P}<.01, *=\mathrm{P}<.05$

ANOVA analyses were done on various domains of commitment as well as overall commitment in relation to job hierarchy and job tenure.

On affective commitment, main effect for job hierarchy was found significant $[\mathrm{F}(2,234)=$ 3.74, $\mathrm{P}<.05$ ], which revealed that officers showed high degree of affective commitment ( $\mathrm{M}$ $=23.61)$ than sub-inspectors $(\mathrm{M}=23.38)$ and constables $(\mathrm{M}=21.36)$ respectively (Fig. 1$)$.

Main effect for job tenure was also found to be significant $[\mathrm{F}(1,234)=7.79, \mathrm{P}<.01]$, which revealed that employees belonging to short job tenure group reported lesser affective

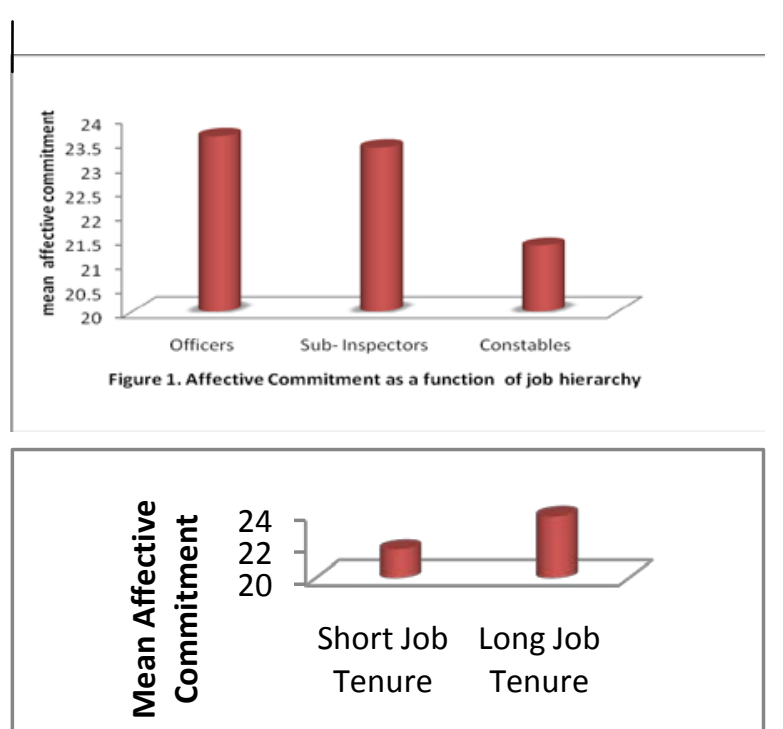

Figure 2. : Affective Commitment as 
commitment $(M=21.76)$ than long job tenure employees $(M=23.81)$ (Fig. 2).

Furthermore, results are shown in Table 1 and Fig. 3, on normative commitment, main effect for job hierarchy $[\mathrm{F}(2,234)=4.89, \mathrm{P}<.01]$ was found to be significant. Results denote that officers reported high normative commitment (M $=22.95)$ than sub-inspectors $(\mathrm{M}=22.81)$ and constables $(\mathrm{M}=20.93)$ respectively.

Main effect for job tenure was also found to be significant $[\mathrm{F}(1,234)=8.86, \mathrm{P}<.01)$. Results indicated that employees of long job tenure group expressed higher level of normative commitment $(\mathrm{M}=23.11)$ than short job tenure group $(\mathrm{M}=$ 21.35) (Fig. 4).

Job hierarchy $\mathrm{x}$ job tenure interaction effect (Fig. 5) was also found significant $[\mathrm{F}(2,234)=5.29$, $\mathrm{P}<$.01]. The result indicated that officers belonging to long job tenure group showed more normative commitment $(\mathrm{M}=24.46)$ than constables $(\mathrm{M}=22.54)$ and sub inspectors $(\mathrm{M}=$ 22.34). Contrary to this, in case of short job tenure group sub inspectors reported high level of normative commitment $(M=23.28)$ than officers $(\mathrm{M}=21.44)$ and constables $(\mathrm{M}=19.34)$.

Results are shown in Table 1, on overall commitment, main effect for job hierarchy was found significant $[\mathrm{F}(2,234)=5.48, \mathrm{P}<.01]$, which revealed that sub-inspectors $(\mathrm{M}=68.9)$ and officers $(M=68.64)$ reported high degree of overall commitment than constable $(\mathrm{M}=64.73)$ (Fig. 6).

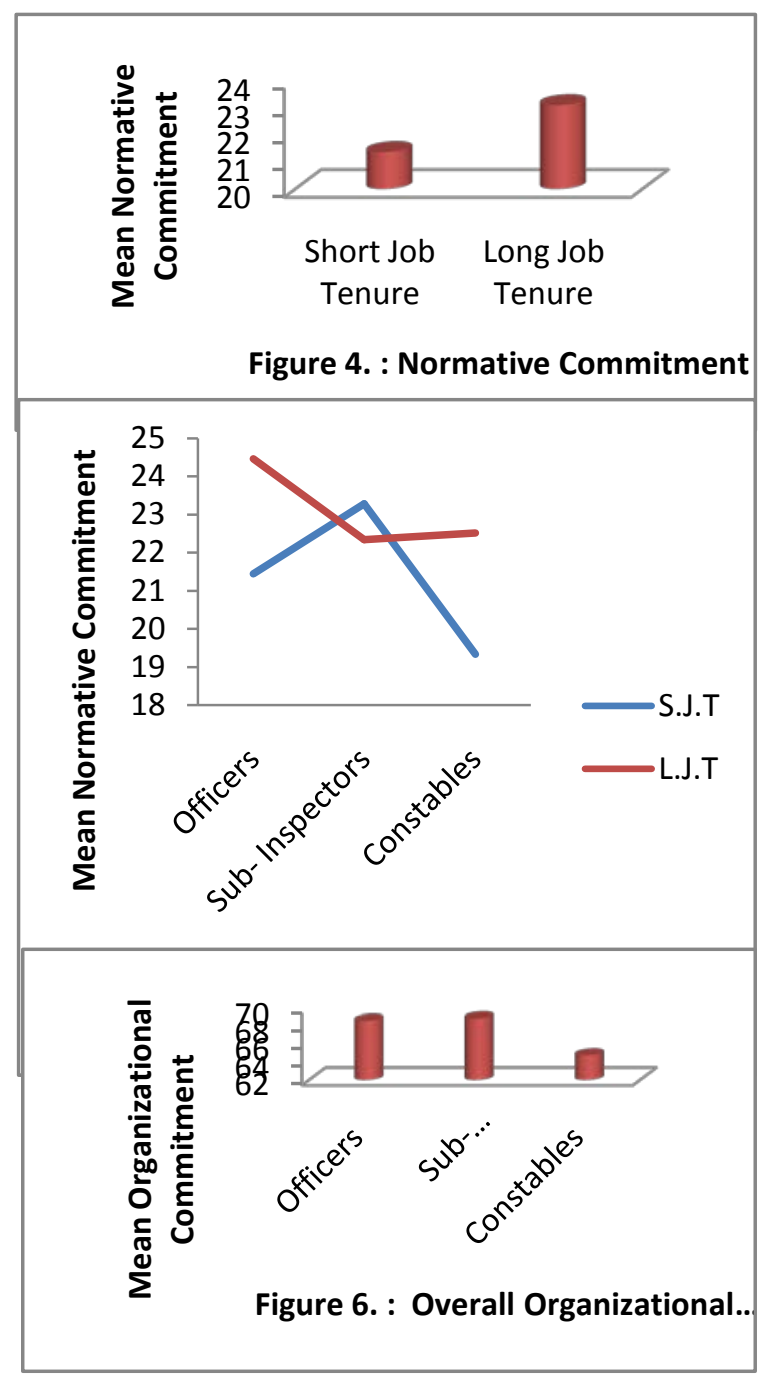

Main effect for job tenure was also found to be significant $[\mathrm{F}(1,234)=8.28, \quad \mathrm{P}<.01]$, which indicated that employees belonging to long job 
tenure reported high overall commitment $(M=69.08)$ than short job tenure $(M=65.76)$ (Fig. 7$)$.

Further, significant job hierarchy $\mathrm{x}$ job tenure interaction effect (Table 1 \& Fig. 8) [F $(2,234)=5.28, \mathrm{P}<.01]$ indicated that officers belonging to long job tenure expressed more commitment $(\mathrm{M}=71.46)$ than sub-inspectors $(\mathrm{M}=$ 67.93) and constables $(M=67.85)$. Contrary to this, in case of short job tenure, sub-inspectors showed high level of overall commitment $(M=69.87)$ than officers $(\mathrm{M}=65.82)$ and constables $(\mathrm{M}=61.60)$.

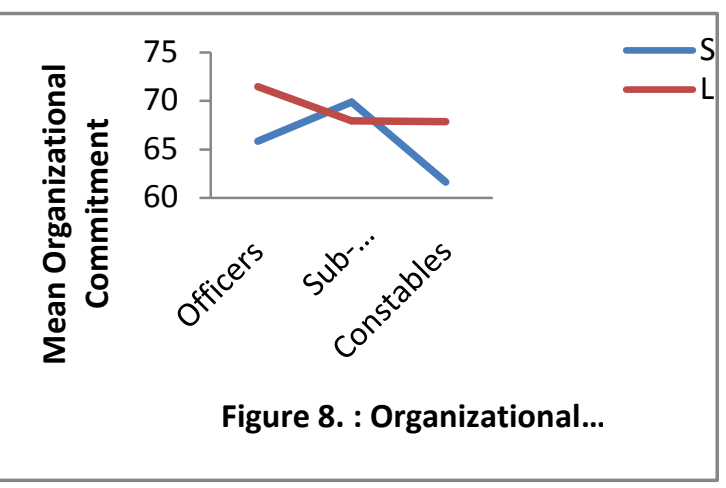

\section{DISCUSSION}

The findings of ANOVA indicate that the level of organizational commitment (overall and domain wise) varied across different groups of police employees.

Present result evinced that officers expressed more affective commitment than sub-inspectors and constables. Furthermore, long job tenure group reported more affective commitment than short job tenure group. Findings are interpreted below in the light of others researches.

Numerous studies evinced that organizational structure and organizational factors influence the level of affective commitment (Bateman \& Strasser, 1994; Mathieu \& Zajac, 1990; Morris \& Steers, 1980). Study conducted on a public sector unit revealed that executives were more committed to their organization than supervisors (Pattanayak, Mishra and Mishra, 1993). Benkhoff (1997) also found organizational commitment to increase with hierarchical position in an organization. Tiwari and Mishra (2008) found that railway officers showed more affective commitment than clerks and class $4^{\text {th }}$ employees. Results of others studies underlying psychological theme (Eizenberge, Hundtrington, Hutchison \& Sowa, 1986; Guzzo, Noonan \& Eiron, 1984) suggest strong links between employee perceptions of support and affective commitment to the organization. Singh (2012) pointed out that officers of police organizations have greater affective commitment than that of other counter parts.

Results further indicated that normative commitment was found greater in officers than subinspectors and constables. Significant main effect for job tenure indicated that employees of long job tenure reported more normative commitment than the employee of short job tenure. Apart from this, job hierarchy $x$ job tenure interaction effect (Fig. 5) denotes that officers of long job tenure expressed more normative commitment than constable and sub-inspectors. However, in case of short job tenure sub-inspectors reported more normative commitment than officers and class $4^{\text {th }}$ employees. This finding is supported by other studies (Mishra \& Srivastava, 2000; Tiwari, 2006; Singh, 2012). 


\section{A Study on Organizational Commitment of Police Employees}

Findings of present study can be validated on the basis of Weiner's model of commitment, which is based on behavioural intention and places commitment within a motivational frame work that distinguishes between instrumental beliefs and beliefs about social norms. Real commitment derives from internalized narrative beliefs. Such values based on normative commitment plus instrumental motivation, determines behavioural intention and organization related behaviour. Findings of present study can also be validated on the basis of three pillar model of commitment propounded by Martin and Nicholls (1987). First pillar is a sense of belongingness to the organization created by officers through ensuring that the work force is informed, involved and sharing in success. Second, a sense of excitement in job, it means improved results will not be achieved unless employees may also feel a sense of excitement about their work, which results in the motivation to perform well. This sense of excitement can be achieved by appealing to the higher level needs of pride, trust, and accountability. Last pillar is confidence in management officers, it shows the respect of employees towards officers are enhanced through attention to authority, dedication and competence. Thus, finally it shows how a wide variety of initiatives taken by officers fit into a coherent picture all pulling in the same direction and mutually reinforcing, it shows, the sense of belonging and excitement can be frustrated if workers do not have respect for and confidence in managerial leadership. This respect is enhanced through attention to authority dedication and competence. Thus, finally it shows how a wide variety of initiatives taken by officers/management fit into a coherent picture all pulling in the same direction and mutually reinforcing.

\section{CONCLUSION AND RECOMMENDATIONS}

1- Officers reported greater affective commitment than sub inspectors and constables.

2- Officers showed high level of normative commitment as compared to sub- inspectors and constables.

3- Sub - inspectors and officers reported high level of overall organizational commitment.

On the basis of these findings, certain recommendations have been made:

- Authorities of the police organization should pay an attention to create a better quality of work place and by providing innovations and stimulation in job and better opportunity of personnel growth, which would enhance the level of commitment in employees.

- Government should pay an attention to maximize payment for lower employees as compared to similar rank employees of other organization.

- Higher authorities of the police organization should pay an attention to create a healthy work environment.

- Police organization should apply managing tactics for solving the behavioral and interpersonal problem.

- Officers and followers should follow more socially approved behavior with colleague, followers and public. 


\section{REFERENCES}

Amsa ,P.and Punekar,V.B. (1985).A value-based conceptual model of commitment to work: An empirical validation. Indian Journal of Industrial Relations,21(1),16-29

Angel,H.L and Perry,J.L (1981).An empirical assessment of organizational commitment and organizational effectiveness .Administrative Science Quarterly,21,1-14.

Allen, N and Meyer,J.P (1990) The Measurement and antecedents of affective, continuance and normative commitment to the organization. Journal of Occupational Psychology, 63(1), 1-18.

Allen, N. J. \& Meyer, J. P. (1996). Affective, continuance, and normative commitment: An examination of construct validity. Journal of Vocational Behavior, 49, 252-276.

Bateman,T.S and Strassor,S. (1994). Longitudinal analysis of the antecedents of organizational commitment. Academy of Management Journal, 27 (1) 95-112.

Benkhoff,B. (1997b) “Ignoring commitment is costly: New approaches to establish the missing Human Relation,Vol,50 No. 6 pp. 701-26.

Bhattacharya. R and Verma.O.P (1988), Job satisfaction as a function of organizational commitment,need satisfaction and managerial respect. Managerial Psychology, 8(1).35-41.

Bruning, N.S., and Snyder, R.A (1981). Predictors of work related competence : Are they different for Men VS. Women? Proceedings of American Institute for Decision Sciences,1, 350-352.

Eisenberger, R., Hutington, R., Hutchsion, S., and Sowa, D. (1986). Perceived organizational support. Journal of Applied Psychology, 71 (30, 500-507).

Gregersen,H.B and Black, J.S (1992), “Antecedents to commitment to a parent company and a foreign operation”, Academy of Management Journal, Vol. 35, No. 1 , pp 65-90.

Guzzo, R.A., and Noonan, K.A. (1994). Human resource practices as communication and psychological contracts. Human Resources Management, 33, 462-497.

Hellriegel,D., slocum, J. and Woodman, R (1995), Organizational Behaviour, West Publishing st. Paul, MN.

Khan, S.M., and Mishra, P.C. (2002). Need satisfaction and organizational commitmentcanonical correlation analysis. Journal of Community Guidance and Research, 199208.

Mathieu, J. And Hamel, D. (1989), “A cause model of the antecedents of organizational commitment among professionals and non professionals,” Journal of Vocational Behaviour, Vol.34,pp. 299-317

Mathieu, J.E., and Zajac, D.M. (1990). A review and meta-analysis of antecedents, correlates and consequences of organizational commitment, Psychological Bulletin, 108; 171-194.

Meyer, J.P., and Allen, J.P. (1991). A three component conceptualization of organizational commitment. Human Resource Management Review, 1, 61-98. 


\section{A Study on Organizational Commitment of Police Employees}

Meyer,J.P., Allen,N.J. and Smith,C.A (1993).Commitment to organizations and occupational extension and test of a three component conceptualization. Journal of Applied Psychology.78 (4), 538-551.

Mc Caul, H.S., Hinsz, V.B and Mc Caul, K.D (1995) “Assessing Organizational commitment an employee's global attitude towards the organization” Journal of applied Behaviour science, Vol.31 No. 1 pp 80-90.

Mohan,R.P and Srivastava,R.C (1986).Organizational commitment in relation to certain job attitudes. Indian Journal of Industrial Relations,21 (4) , 462-472

Morris, J.H., and Steers, R.M. (1980). Structural influences on organizational commitment. Journal of Vocational Behaviour 17, 50-57.

Mottaz,C.J. (1988). Determinants of organizational commitment. Human Relations,41,467-482.

Mowday, R., Steers, R., and Porter, L. (1979). The measurement of organizational commitment. Journal of Vocational Behavior, 14, 224-247_._-

O’ Reilly,C, Chatman, J. And Caldwell, D.P (1991), "People and Organizational Culture: a profile comparison approach to assessing person- organization fit” Academy of management Studies, Vol.34, pp 487 - 516.

Padki, R. and Gandhi,O.P (1981).Organizational climate and identification with work and organization. Managerial Psychology,2(1),46-60.

Pattanayak, Mishra, S.K., and Mishra, P.K. (1993). Psychological well- being and organizational commitment: A study on Public Sector. Indian Journal of Applied Psychology,30,2431.

Randall, D.M. (1990). The consequences of organizational commitment: Methodological investigation. Journal of Organizational Behavior, 11,361-378.

The Pennsylvania State University (2011). Lesson 12: Work and organizational commitment: Introduction to Work and Organizational Commitment. Retrieved from Lecture Notes Online Web site

Scholl,R.W. (1981). Differentiating commitment from expectancy as a motivating force. Academy of Management Review, 6,589-599.

Salancik, G.R. (1977).Commitment and the control of organizational behavior and belief.In B.M.taw and G.R.Salancik(Eds.).New Directions in Organization Behaviours pp.154.

Steers, R.M. (1977). Antecedents and outcomes of organizational commitment. Administrative Science Quarterly, 23, 40-64.

Singh, A. P (2012).Correlates of Organizational Commitment; A study on police personnel, Radha Publication, Delhi, India.

Singh,P and Das,G.S (1978).Organizational culture and its impact on commitment to work. Indian Journal of Industrial Relations,13(4), 511-524.

Sayeed O.B (2001) organizational commitment and conflict 'Studies in Healthy Organizational Processes, Sage Publication, New Delhi.

Snyder, R. A., and Bruning, N.S. (1979). Sex differences in perceived competence: An across organizations study. Administration in Social Work,3, 349-358. 


\section{A Study on Organizational Commitment of Police Employees}

Tiwari, S. K. and Mishra, P. C. (2008). Work stress and health as predictors of organizational commitment. Indian Academy of Applied Psychology.

Tiwari, S.K. (2006). Psychological correlates of organizational commitment: a study on railway personnel. Published Doctoral Dissertation. Lucknow University, Lucknow.

Verma,O.P (1986). Organizational commitment as a function of managerial respect .Asian Journal of Psychology and education, 17 (1), 1-6.

Weinner,Y and Vardi,Y (1980) Relationships between job , organization and career commitments and work outcomes: An integrative approach. Organizational Behaviour and Human Performance, 26,81-96.

Weinner,Y. (1982). Commitment in organizations: A normative view. Academy of Management Review.7, 418-428. 